\title{
Development of the Conceptual Model for Estimating Apartment Sales Price
}

\author{
Kim Ki-Hyuk, Do Sung-Lok, Lee Donghoon
}

\begin{abstract}
In this study, factors affecting the apartment sales rate were selected through review of existing literature and expert advice. Then, the weight of each influence factor was calculated through the survey. In addition, causal maps of each factor on the prevalence rate were drawn to understand the influence relationship of each influential factor. Finally, this study proposes a new apartment sale price calculation method that correctly applies the weights of the influential factors. First, the influencing factors were classified according to apartment size, residential environment, surrounding environment, apartment characteristics, and social environment at the time of purchase. According to the survey results, the main-factors that have the greatest impact on the apartment sale rate are analyzed as surroundings environment, and the main-factor that have the least impact are analyzed as apartment size. Finally, this study proposes a method of estimating the apartment price in the order of 'evaluating each factor, standardization of score using formula, standardized score summation, and determine sale price'. It is important to set the sensitivity of each factor.
\end{abstract}

Keywords : apartment, sale price, sale ratio, simulation, feasibility study

\section{INTRODUCTION}

$M_{\text {any factors play into the failure of a construction }}$ project. Overall cost may overshoot than planned or construction period may be extended. For an apartment, the sales ratio may not reach the target, which may lead to a project failure. In such case, the construction firm takes a major financial blow and, in some extreme cases, leads to bankruptcy. In order to avert these issues, construction firms perform a feasibility study prior to engaging in a project. Through it, a firm is able to determine whether a construction project will be profitable and exclude ones that has low profitability. In 2004, the Construction Economy Research Institute of Korea, or CERIK, conducted a survey, as well as literary review and interview, on feasibility studies performed by 96 construction companies. Of those, $96.9 \%$ replied that they regard feasibility study important in proceeding with a construction. Fig. 1 represents the importance of business process deemed by each company. Land acquisition and validation were deemed most important, each occupying

Revised Manuscript Received on July 22, 2019.

Kim Ki-Hyuk, Department of architectural engineering, Hanbat National University, Deajeon, Republic of Korea. Email: knn200@naver.com

Do Sung-Lok, Department of facility engineering, Hanbat National University, Deajeon, Republic of Korea. Email: sunglokdo@hanbat.ac.kr

Lee Donghoon*, Department of architectural engineering, Hanbat National University, Deajeon, Republic of Korea. Email: donghoon@hanbat.ac.kr
$18.2 \%$ and $16.6 \%$, respectively. $79.2 \%$ answered that feasibility study had definitive impact on the success or failure of a business. the journal, rectification is not possible.

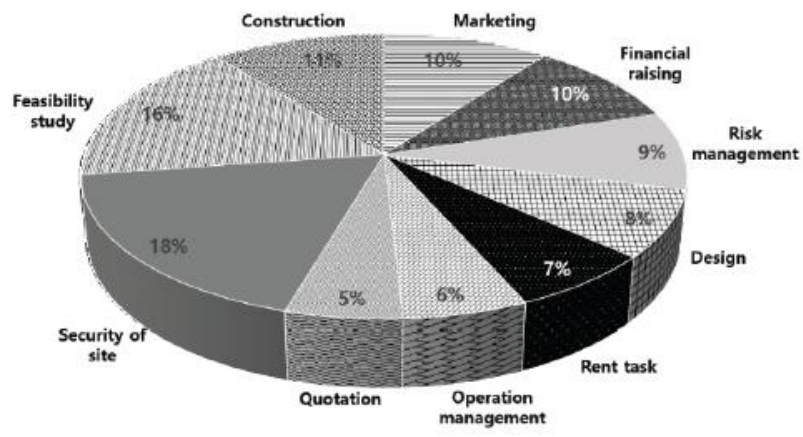

Fig. 1. Project success factors that firms think[1]

Even though feasibility study had significant impact on the project, most construction companies lacked capacity in conducting the study. Table 1 represents difficulties faced by companies in conducting a feasibility study.

Table- I: Problems of feasibility study[1]

\begin{tabular}{cc}
\hline Problems & Ratio(\%) \\
\hline Tight analysis schedule & 19.1 \\
\hline $\begin{array}{c}\text { Lack of specialists } \\
\text { insufficient }\end{array}$ & 18.5 \\
\hline $\begin{array}{c}\text { Judgment on qualitative factors such } \\
\text { as laws or civil complaints }\end{array}$ & 17.4 \\
\hline Persuading decision makers & 14.6 \\
\hline $\begin{array}{c}\text { Communication with other } \\
\text { departments or outside firms }\end{array}$ & 10.1 \\
\hline Secure the required budget & 6.2 \\
\hline Total & $\mathbf{1 0 0 . 0}$ \\
\hline
\end{tabular}

The result indicated that tight scheduling of the study, lack of experts, and inadequate system were major difficulties when conducting a feasibility study. To deal with expert deficiency, larger companies installed a division specifically for feasibility study. It has become more and more expertized with $56 \%$ of the force being core members. Therefore, it is anticipated that the new feasibility study system with compressed analysis period and enhanced reliability will serve to offer significant contribution in improving our overall capability in feasibility study. Also, Table 2 represents the survey result using AHP (Analytical Hierarchical Process) in existing study, which indicates that the sale price of an apartment has the most influence in purchasing. AHP is a suitable tool for this study because it can handle all qualitative and quantitative 
decision making factors[2].

Table- II: The weight of factors affected by apartment purchasing decisions[3]

\begin{tabular}{|c|c|c|c|c|}
\hline $\begin{array}{c}\text { Main } \\
\text { factors }\end{array}$ & Weight & Sub-factors & Weight & $\begin{array}{c}\text { Final } \\
\text { weight }\end{array}$ \\
\hline \multirow{3}{*}{$\begin{array}{l}\text { Economic } \\
\text { factor }\end{array}$} & \multirow{3}{*}{0.439} & Sale price & 0.548 & 0.192 \\
\hline & & $\begin{array}{l}\text { Investment } \\
\text { value }\end{array}$ & 0.263 & 0.092 \\
\hline & & $\begin{array}{l}\text { Unkeep } \\
\text { expenses }\end{array}$ & 0.189 & 0.066 \\
\hline \multirow{4}{*}{$\begin{array}{l}\text { Location } \\
\text { factor }\end{array}$} & \multirow{4}{*}{0.340} & Transportation & 0.301 & 0.102 \\
\hline & & $\begin{array}{l}\text { Educational } \\
\text { environment }\end{array}$ & 0.459 & 0.156 \\
\hline & & Facilities & 0.088 & 0.030 \\
\hline & & Accessibility & 0.152 & 0.052 \\
\hline \multirow{6}{*}{$\begin{array}{c}\text { Housing } \\
\text { characteristics }\end{array}$} & \multirow{6}{*}{0.073} & $\begin{array}{c}\text { Orientation } \\
\text { And } \\
\text { alignment }\end{array}$ & 0.243 & 0.018 \\
\hline & & $\begin{array}{l}\text { Household } \\
\text { number }\end{array}$ & 0.079 & 0.006 \\
\hline & & View & 0.236 & 0.017 \\
\hline & & Area & 0.201 & 0.015 \\
\hline & & Plan plan & 0.157 & 0.011 \\
\hline & & Grade of finish & 0.084 & 0.006 \\
\hline \multirow{2}{*}{$\begin{array}{c}\text { Financial } \\
\text { environment } \\
\text { factors }\end{array}$} & \multirow[b]{2}{*}{0.118} & Loan interest & 0.496 & 0.059 \\
\hline & & $\begin{array}{c}\text { Real estate } \\
\text { business }\end{array}$ & 0.504 & 0.060 \\
\hline \multirow{2}{*}{$\begin{array}{c}\text { Institutional } \\
\text { Policy } \\
\text { factors }\end{array}$} & \multirow{2}{*}{0.053} & $\begin{array}{l}\text { House-related } \\
\text { tax system }\end{array}$ & 0.660 & 0.035 \\
\hline & & $\begin{array}{l}\text { Loan } \\
\text { regulation }\end{array}$ & 0.340 & 0.018 \\
\hline \multirow{3}{*}{ Etc. } & \multirow{3}{*}{0.066} & Brand & 0.219 & 0.015 \\
\hline & & $\begin{array}{c}\text { Social } \\
\text { environment }\end{array}$ & 0.450 & 0.030 \\
\hline & & $\begin{array}{l}\text { Sale time and } \\
\text { condition }\end{array}$ & 0.331 & 0.022 \\
\hline Total & 1.000 & Total & & 1.000 \\
\hline
\end{tabular}

Because sale price is the most instrumental factor in determining sale rate for apartments, settling on modest sale price through feasibility study is important to raise sale rate. Regrettably, many Korean companies lack competence in that area. Moreover, many of the methods used by Korean companies to determine sale price are faulty, leading to deficient sales rate and project failures. In particular, the case of small and medium-sized cities without precedent in business, there were many problems with the new project due to lack of reference data[4]. In that notion, the purpose of this study is to identify the factors influential to sale rate to determine optimal sale price, analyze the respective relative importance of each factor through survey study and propose a new way to determine sale price incorporating the factors befitting their respective relative importance.

In this study, factors influencing sale rate will be explored to build a causal loop diagram for a simulation. First, feasibility study and simulation will be studied through theoretical contemplation. Then, existing studies will be analyzed through literary review to determine the problems of current method of sale price calculation. Factors influential to

apartment purchase will be identified and made into a causal loop diagram based on their inter-correlation. Relative importance of each factor will be determined and an improved new method to determine sale price will be proposed.

\section{THEORETICAL REVIEW}

\section{A. Feasibility Study}

A feasibility study, also called validation review, is a process for making a proper assessment of the practicality to uncover the strengths and weaknesses of a business or project. A construction project is a high risk business. It is a complex venture with sale price, government policy, location, accessibility, economy and many other factors incorporated.

In general, a feasibility study is comprised of 'goal setting $\rightarrow$ data collection and analysis $\rightarrow$ development concept setting $\rightarrow$ determination of proper use and size $\rightarrow$ planning and design $\rightarrow$ profitability study $\rightarrow$ feasibility study and determination of alternative'. The process is not in series, but rather inter-compatible to one another and requires feedback[5].

\section{B. Simulation}

According to the Standard Dictionary of NIKL, a simulation is an approximate imitation of the operation of a complex problem or social phenomenon through developing a model for interpretation and resolution. As expounded, a feasibility study is a crucial measure in a construction project, which may govern the success and failure of a project. A simulation program is a great way to conduct a feasibility study that is to predict an uncertain future. It is a tool for predicting the future not with exact information but with various considerations. It is the most optimal tool for a feasibility study. What is most important in developing a model is to understand the feedback structure of each factor and build a causal loop diagram which aids in visualizing how different factors at play are interrelated. The diagram consists of positive and negative feedback loops. A positive feedback loop indicates a reinforcing feedback loop and a negative feedback loop indicates a balancing feedback loop[6].

\section{Literary Review}

In the existing study, they studied Korean reports and literature on feasibility study, proposed a new assessment model incorporating economy, analyzed 22 samples and claimed to involve economy as a variable in the feasibility study. According to existing study, the coefficient of correlation between actual and experimental values was high at 0.815 and that significance and economy must be included in the feasibility study[7].

In other study, they selected 16 previous studies out of 60 and found out their problems and conducted his own research to provide improvement measures. They pointed out that previous studies were unwarrantedly focused on income and expenditure analysis and lacked investigation on factors closely linked to habitability of the users. They sorted a feasibility study process into preliminary review, 
i.e. business goal setting, before-business data collection, and determining and defining of developmental issues, and main review, i.e. final data analysis, final development planning, and business performance prediction. He also explored relative importance of each factors used by previous researchers. That study, they pointed out the following problems:

- Feasibility study was conducted solely on current developmental conditions and not on market economy;

- Key factors established were to maximize profit from supplier's position rather than the position of the consumer; and

- Average utilization rate of assessed factors was $46.5 \%$, lacking the necessary in-depth and comprehensive review. The rate must be increased up to $60 \%$.

Moreover, that study stressed that we need further studies focusing on eliminating risk factors in advance through a comprehensive and in-depth approach and retaining macroscopic perspective that systemize profit making for both supplier and consumer[5].

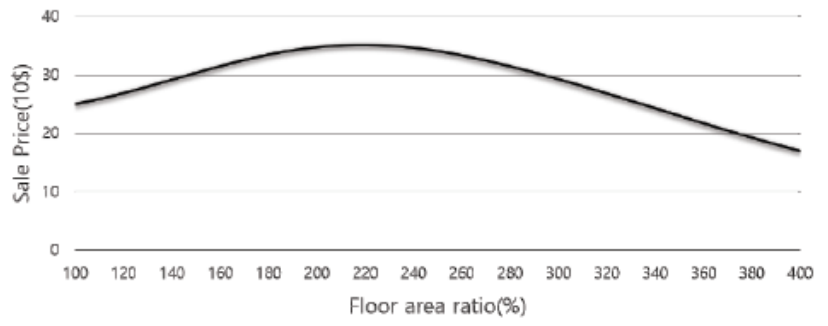

Fig 2. Result of simulation[8]

It was concluded that the floor area ratio of an apartment that maximizes residential value is around $230 \%$ and that the floor area ratio which maximizes feasibility is 300 to $340 \%$ without type raise and 375 to $380 \%$ with type raise[8].

\section{RESULT AND DISCCUSION}

\section{A. Identifying Factors to Apartment Sale Rate and Their Significance}

In this study, according to hedonic price theory that the house price is determined by the total value of the characteristics constituting the house[9], factors influential to apartment sale were identified from literary review and expert advice and a causal loop diagram was developed for building a simulation program to determine sale price. The factors affecting housing price can be divided into residential property, complex property, and local property[10]. Identified purchased factors are illustrated in Table 3, and the causal loop diagram is illustrated in Figure 3. Of the purchase factors, sale price is the foremost variable to sale rate, but the ultimate purpose of this study is to determine sale price and was removed from consideration. The factors can be largely categorized into apartment size, residential environment (indoor), surrounding environment (outdoor), apartment characteristics, and social environment at the time of purchase. Subfactors to apartment size include number of floors, unit size and number of complexes; and subfactors to residential environment include soundproofing, interior finishing material, and insulation performance; and subfactors to surrounding environment include accessibility to market

and amenities, educational environment, and public transportation; and subfactors to apartment characteristics include use of eco-friendly energy, appearance and outdoor facilities, and brand; and social environment at the time of purchase include government real estate policy and interest rate.

Table- III: Selection of apartment purchasing affect factors Main factors Sub-factors

Apartment size Number of floors, unit size, number of complexes

Residential environment

Residential include soundproofing, environment(indoor) interior finishing material, insulation performance

Accessibility to market and

Surrounding

environment(outdoor) amenities, educational environment, public transportation

Use of eco-friendly energy,

Apartment characteristics appearance outdoor facilities, brand

Social environment at the Government real estate time of purchase policy, interest rate

On the basis of information above, a survey was conducted, using AHP technique, on domestic construction companies to determine the relative importance of each factor. Table 4 and Table 5 tabulates the surveyees. There were a total of 39 surveyees. Actual work experience was regarded most important in feasibility study and those over 60 years of age was set at $48.718 \%$.

Table- IV: Proportion of surveyees(age)

\begin{tabular}{ccc}
\hline Age & Persons & Ratio(\%) \\
\hline 20 's & 4 & 10.256 \\
\hline 30 's & 7 & 17.949 \\
\hline 40 's & 1 & 2.564 \\
\hline 50 's & 8 & 20.513 \\
\hline More than 60's & 19 & 48.718 \\
\hline
\end{tabular}

And the ratio of those with 20 years of work experience in the field was set highest at $71.795 \%$.

Table- V: Proportion of surveyees(career)

\begin{tabular}{ccc}
\hline Career & Persons & Ratio(\%) \\
\hline 0years $~$ 5years & 10 & 25.641 \\
\hline 5years $\sim$ 10years & 1 & 2.564 \\
\hline 10years $\sim$ 15years & 0 & 0.000 \\
\hline 15years $~ 20$ years & 0 & 0.000 \\
\hline 20years $~$ & 28 & 71.795 \\
\hline
\end{tabular}


The result of AHP survey disclosed that residential environment was most important and apartment size was least important. As for the final relative importance of subfactors, during a purchase, interest rate was most important and floor was least important.

Table- VI: Result of calculating weight of each factors

\begin{tabular}{|c|c|c|c|c|}
\hline $\begin{array}{l}\text { Main- } \\
\text { factor }\end{array}$ & $\begin{array}{l}\text { Weight } \\
\text { (A) }\end{array}$ & $\begin{array}{l}\text { Sub- } \\
\text { factor }\end{array}$ & $\begin{array}{l}\text { Weight } \\
\text { (B) }\end{array}$ & $\begin{array}{c}\text { Final } \\
\text { Weight } \\
\text { (A X } \\
\text { B) }\end{array}$ \\
\hline \multirow{3}{*}{$\begin{array}{l}\text { Apartment } \\
\text { Size }\end{array}$} & \multirow{3}{*}{0.146} & $\begin{array}{l}\text { Number } \\
\text { Of } \\
\text { Floors } \\
\end{array}$ & 0.285 & 0.042 \\
\hline & & Unit size & 0.378 & 0.055 \\
\hline & & $\begin{array}{l}\text { Number } \\
\text { Of } \\
\text { complexes }\end{array}$ & 0.337 & 0.049 \\
\hline \multirow{3}{*}{$\begin{array}{l}\text { Residential } \\
\text { Environment } \\
\quad \text { (indoor) }\end{array}$} & \multirow{3}{*}{0.215} & $\begin{array}{c}\text { Residential } \\
\text { Environment } \\
\text { Include } \\
\text { Soundproofing }\end{array}$ & 0.349 & 0.075 \\
\hline & & $\begin{array}{c}\text { Interior } \\
\text { Finishing } \\
\text { Material } \\
\end{array}$ & 0.316 & 0.068 \\
\hline & & $\begin{array}{c}\text { Insulation } \\
\text { Performance }\end{array}$ & 0.335 & 0.072 \\
\hline \multirow{3}{*}{$\begin{array}{l}\text { Surrounding } \\
\text { Environment } \\
\text { (outdoor) }\end{array}$} & \multirow{3}{*}{0.268} & $\begin{array}{c}\text { Accessibility } \\
\text { To market and } \\
\text { amenities }\end{array}$ & 0.369 & 0.099 \\
\hline & & $\begin{array}{c}\text { Educational } \\
\text { Environment }\end{array}$ & 0.261 & 0.070 \\
\hline & & $\begin{array}{c}\text { Public } \\
\text { transportation }\end{array}$ & 0.371 & 0.099 \\
\hline \multirow{3}{*}{$\begin{array}{c}\text { Apartment } \\
\text { Characteristics }\end{array}$} & \multirow{3}{*}{0.189} & $\begin{array}{c}\text { Use of } \\
\text { Eco-friendly } \\
\text { Energy } \\
\end{array}$ & 0.336 & 0.064 \\
\hline & & $\begin{array}{l}\text { Appearance } \\
\text { outdoor } \\
\text { facilities }\end{array}$ & 0.305 & 0.058 \\
\hline & & brand & 0.359 & 0.068 \\
\hline \multirow[t]{2}{*}{$\begin{array}{c}\text { Social } \\
\text { environment }\end{array}$} & \multirow[t]{2}{*}{0.181} & $\begin{array}{c}\text { Government } \\
\text { Real estate } \\
\text { Policy }\end{array}$ & 0.424 & 0.077 \\
\hline & & Interest rate & 0.576 & 0.104 \\
\hline Total & 1.000 & total & & 1.000 \\
\hline
\end{tabular}

\section{B. Development Simulation Causal Loop Diagram}

Just as interior finishing materials influence soundproofing, each subfactor not only influences other subfactors within an upper level factor but all other subfactors within other upper level factors. For example, subfactors, educational environment and public transportation, are each under a different factor but are influential to one another. Furthermore, all factors influence the sale rate and can be expressed as illustrated in Figure 3. Those with ' + ' sign indicate a positive influence and those with '-' sign indicate a negative influence. For example, degree of soundproofing improves if better interior finishing materials are used. In this case, ' + ' sign was used. On the other hand, insulation becomes poorer as the unit size increases. In this case, '-' sign was used.

Here, the sale price is not a fixed value but determined by the construction company and is, therefore, determined separately as an independent variable. What we must understand is that the sale price is closely related to the sale rate. The sale rate raises as the sale price drops, but the sale rate drops as the sale price rises. As evident in Table 2, sale price is an important factor when purchasing an apartment. To raise the sale rate, it is crucial to properly control the sale price.

Although the sale price and sale rate are in a negative relationship, excessive sale price discount may cause a loss to the company. One of more plain ways to express a company's profit is multiplying sale price and sale rate. In other words, one of the ways to maximize profit from an apartment project is to determine a proper sale price and achieving target sale rate. For this, many previous studies suggested numerous methods in determining sale price, but most made the error of incorrectly applying the relative importance of purchase factor. In this study, apartment sale price technique applied with proper relative importance of each factor will be proposed.

\section{Suggesting for calculating apartment sale price}

There have been many studies done on how to determine apartment sale price but most of them had distorted the relative importance of each factor. This drawback basically invalidates all relative importance values drawn from previous studies. To resolve this problem, a new method for determining apartment sale price is proposed in this study.

The basis in determining sale price is the price of new neighboring apartments. Therefore, the prices of new neighboring apartments are inspected before setting apartment sale price. Then, sale factors of the new apartment are determined by comparing to those of neighboring apartments or individual assessment. Specific weight of each factor is applied by its relative importance.

Table 5 discloses that different factors influence the decision on apartment purchase differently. 


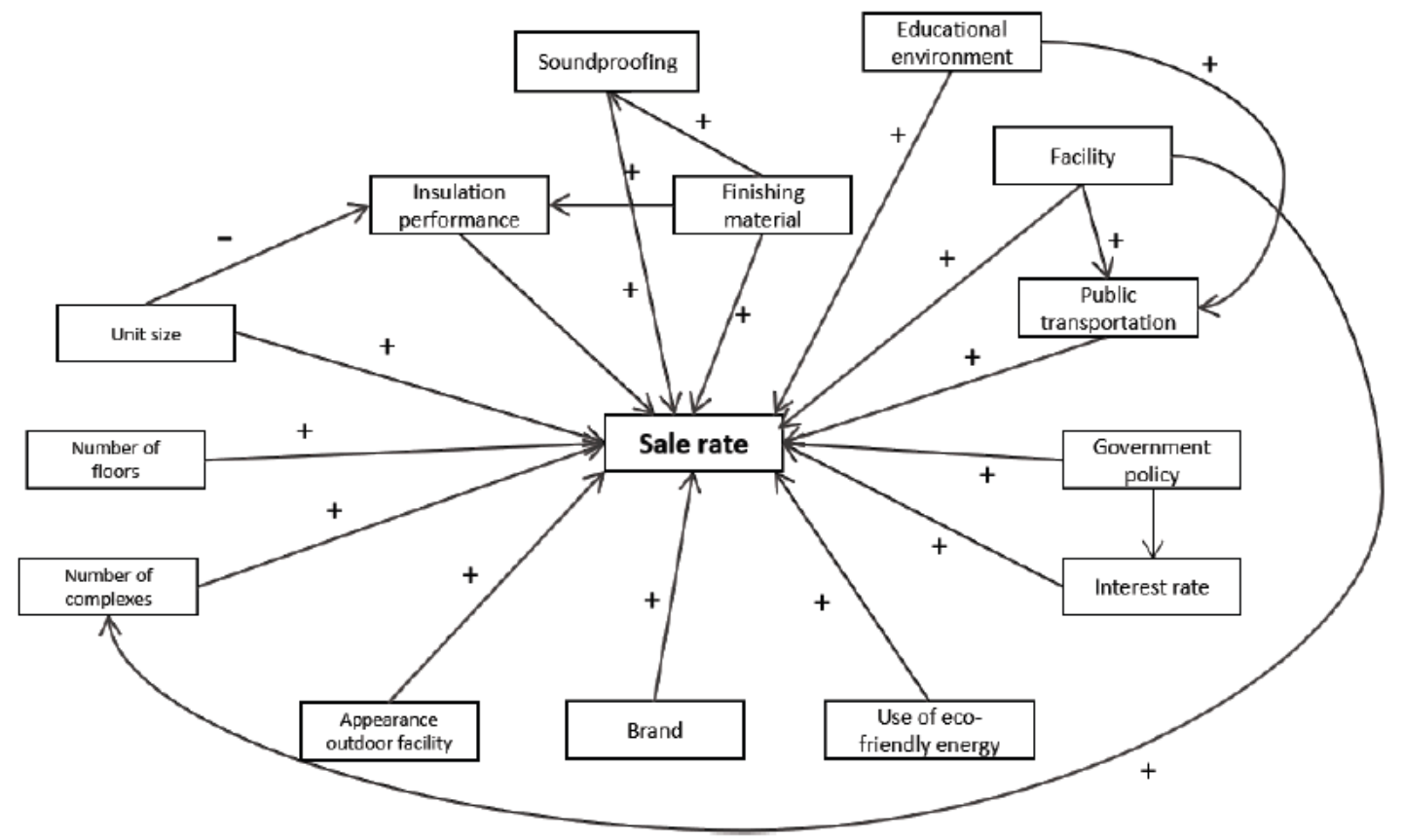

Fig. 3. Casual loop for apartment sale ratio

For example, the influence of social environment at the time of purchase on apartment purchase is trivial at 0.181 , but the influence of surrounding environment on apartment sale is significant at 0.268 . What is important here is not high relative importance of an upper level factor does not warrant high relative importance of its subfactors. For example, interest rate has a low relative importance of 0.104 , whereas its upper level factor, social environment at the time of purchase, has a relative importance of 0.181 . On the other hand, surrounding environment has a higher relative importance of 0.268 , but its subfactor, educational environment, has a relative importance of 0.070 , which is lower than that of interest rate. If we can determine specific weight of each factor, we will be able to come up with an apartment sale price that is the closest to the optimal solution.

In order to determine sale price by applying specific weight on each factor, score segment for each factor must be determined and adjusted. A tornado chart is used to analyze the sensitivity of each factor. It is a type of bar chart used to manage risks and to determine the importance of analyzing and managing the sensitivity of various factors influencing a single factor. To draw a tornado chart, it is important to decide on the segment for each factor, because if the data categories include the smallest range when determining the score for each factor, sensitivity of each factor may be reversed. For example, there will never be a case of soundproofing where $0 \%$ or $100 \%$ of sounds will be blocked. If these ranges are included, when determining soundproofing score, its sensitivity to sale rate will be very high, and thereby, reverse the sensitivity values of the other factors. For this reason, it is important to assume the range of each factor between 90 to $95 \%$. In other words, to assess public transportation, one must examine number of public transportation near the apartment to be built and set 90 to $95 \%$ range as the scoring range when compared to the total number of public transportation in Korea.

\section{Improvement}

The calculation method for sale price proposed in this study has the following problems:

First, it requires data for simulation using causal loop diagram. This study went so far as to present the correlation among the variables in the diagram, but it does not confirm level of influence on one another. Therefore, future studies require how much the variables influence one another.

Second, a study is necessary to standardize the assessment score on the calculation method for apartment sale price. This study only offered the method for calculating sale price and requires exact formula that can be applied to this study.

Third, a study is necessary to verify the calculation method. No verification was made in this study due to lack of data and insufficient research on simulation modeling. This may deteriorate reliability of this study. Therefore, it is important to verify the calculation method for apartment sale price proposed in this study.

Lastly, a clear assessment standard is necessary for each factor. A clear standard during assessment results in data with higher reliability, which will be vital in calculating accurate apartment sale price. Therefore, studies will have to continue on assessment methods proper to each factor.

\section{CONCLUSION}

This study can be summarized as below:

(1) Developing simulation causal loop diagram: In this study, a causal loop diagram for simulation was developed prior to the study on calculating apartment sale price using simulation. To achieve this, a literary review was conducted to examine the factors to sale. 
(2) Proposing calculation method for apartment sale price: Previous studies were analyzed and found that they all made an error of application of specific weight for each factor. To resolve this, a new method was proposed: 'assessment on each factor $\rightarrow$ standardization of assessment score using formula $\rightarrow$ summation of standardized scores $\rightarrow$ calculation of sale price'.

Further improvements necessary can be summarized as below:

(1) Require studies on each factor has on one another

(2) Require studies to standardize assessment scores

(3) Require studies to verify the result of this study

(4) Require studies that make specific proposal on assessment standard for each factor.

Making further progress in consideration of these improvements, a more reliable apartment sale price calculation method which more accurately applies specific weight of purchase factors befitting their relative importance and significantly contribute to advance the capacity in feasibility study for Korean companies which they clearly lack now. Through this, it is anticipated that, the companies will be able to identify an appropriate sale price to achieve planned sale rate and minimize company loss from sale price.

\section{ACKNOWLEDGMENT}

This research was supported by a grant (NRF-2017R1C1B5076057) from the National Research Foundation of Korea by Ministry of Science, ICT and Future Planning.

\section{REFERENCES}

1. O. H. Kwon, J. H. Jung, "An analysis of construction firms' feasibility study," Construction\&Economy Research Institute of Korea, Seoul, 2004, 103 p.

2. B. H. Kwak, "Consistency Check of Pairwise Comparison in Analytic Hierarchy Process:Using the Duplex Outranking Method," Hanyang University, Seoul, 2007, 35p.

3. H. S. Park, "A Feasible Sale Price Assessment Model of Apartment Housing Units Considering Market Price and Buying Power," Kyunghee University, Seoul, 2015, 129p.

4. J. K. Park, Y. K. Cho, S. Y. Lee, "PSM based Price Estimating for Local Mixed-Use Apartment Development," Korea Institute of Construction Engineering and Management, 2014, pp.86-pp.94

5. S. M. Koo, M. W. Jung, "A Basic Study on the Current State and Problems of Feasibility Study:Focused on the Evaluation Criteria of the Existing Relative Researches," The Architectural Institute of Korea, 2007, pp.79-pp.88

6. H. J. Park, "A Study on the Changes of Real Estate Policies and the Market Response Using Casual Maps," Chung-Ang University, Seoul, 2018, 92p.

7. T. K. Ha, S. I. Kim, K. H. Kim, "A Quantitative Housing Project Feasibility Test Model Considering Market Factors," Gyeonggi Research Institute, 2014, pp.5-pp.26

8. C. M. Jung, O. H. Kwon, "A Study on Affecting Price of Apartments and Feasibility by Floor Area Ratio:Focused on Gyeonggi-do Newtown Project Area," Architectural Institute of Korea, 2009, pp.137-pp.144

9. C. M. Park, "Comparative Analysis of Attributes in Determining Housing Price between the Initial Listed Price and Sale Price in Seoul," Chung-Ang University, Seoul, 2008, 55p.

10. C. M. Jung, H. J. Hwang, O. H. Kwon, "Housing Environment and Quality According to the Floor Area Ratio," Gyeonggi Research Institute, Soowon-si, 2009, 106p.

\section{AUTHORS PROFILE}

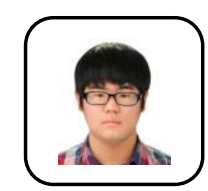

Kim Ki-Hyuk Department of architectural engineering, Hanbat National University, Deajeon

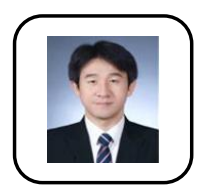

Do Sung-Lok Department of facility engineering, Hanbat National University, Deajeon

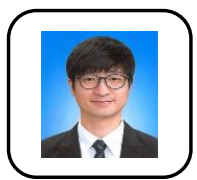

Lee Donghoon Department of architectural engineering, Hanbat National University, Deajeon 